\title{
Drinking Water Quality Impacts on Health Care Expenditures in the United States
}

\author{
Fahad Alzahrani \\ West Virginia University, fa0003@mix.wvu.edu \\ Alan R. Collins \\ West Virginia University, alan.collins@mail.wvu.edu \\ Elham Erfanian \\ West Virginia University, elhamerfanian@mix.wvu.edu
}

Follow this and additional works at: https://researchrepository.wvu.edu/rri_pubs

Part of the Regional Economics Commons

\section{Digital Commons Citation}

Alzahrani, Fahad; Collins, Alan R.; and Erfanian, Elham, "Drinking Water Quality Impacts on Health Care Expenditures in the United States" (2019). Regional Research Institute Working Papers. 193.

https://researchrepository.wvu.edu/rri_pubs/193

This Working Paper is brought to you for free and open access by the Regional Research Institute at The Research Repository @ WVU. It has been accepted for inclusion in Regional Research Institute Working Papers by an authorized administrator of The Research Repository @ WVU. For more information, please contact ian.harmon@mail.wvu.edu. 


\title{
Regional Research Institute West Virginia University
}

\author{
Working Paper Series
}

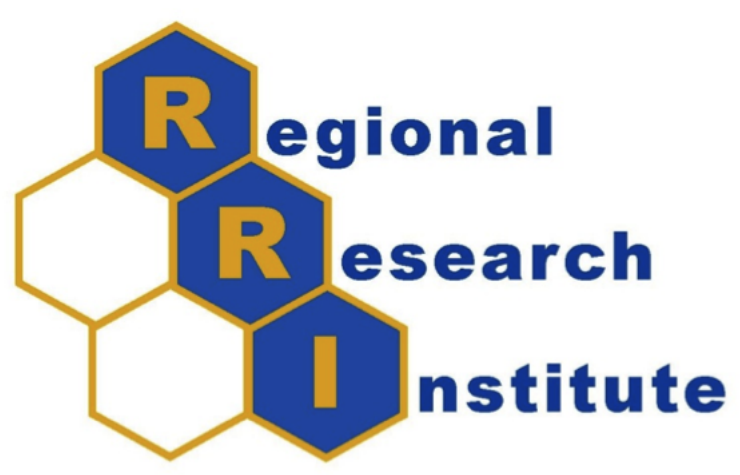

Drinking Water Quality Impacts on Health Care Expenditures in the United States

Fahad Alzahrani, Ph.D. Candidate, Division of Resource Economics and Management, West Virginia University, Morgantown, WV. Agribusiness and Consumer Sciences, King Faisal University, Al-Ahsa, Saudi Arabia, FA0003@MIX.WVU.EDU;

Alan R. Collins, Professor and Interim Director, Division of Resource Economics and Management, School of Natural Resources, West Virginia University, Morgantown, WV;

Elham Erfanian, Ph.D. Candidate, Division of Resource Economics and Management, Regional Research Institute, West Virginia University, Morgantown, WV

Working Paper Number 2019-02

Website address: rri.wvu.edu 


\title{
Drinking Water Quality Impacts on Health Care Expenditures in the United States
}

\author{
Fahad Alzahrani*1 ${ }^{* 1}$ Alan R. Collins ${ }^{\dagger 1}$ and Elham Erfanian ${ }^{\ddagger 1}$ \\ ${ }^{1}$ West Virginia University - WVU
}

April 13, 2019

\begin{abstract}
This paper explores the relationship between episodes of contaminated drinking water and health care expenditures in the United States. The analysis relies on panel data from the 48 contiguous states from 2000 to 2011. We use the population served by public water systems that violate health-based standards of the Safe Drinking Water Act as a proxy for contaminated drinking water. We estimate spatial and non-spatial models and control for factors that may affect per capita health care expenditures including variables that reflect air quality violations along with ability to pay plus demand for and supply of health care services. The results from a Spatial Durbin Model indicate that a $1 \%$ decrease in the percentage of population exposed to drinking water quality violations is associated with reductions in in-state and regional effects equal to $0.005 \%(\$ 0.32)$ and $0.035 \%(\$ 2.26)$ of per capita health care expenditures, respectively. Drinking water violations have a larger impact on expenditures than air quality violations (whose effects are not statistically different from zero). However, compared to other factors, such as Medicare enrollment and income, the impact of these violations on health care expenditures is relatively small. We find that regional health care expenditure impacts from drinking water violations are substantially greater than in-state impacts. Thus, a regional approach is recommended to addressing drinking water quality improvements.
\end{abstract}

Keywords: Water Quality, Health Care Expenditures, Spatial Econometrics, Spillover Effects JEL Classification: Q53, I11, C31

*fa0003@mix.wvu.edu

†alan.collins@mail.wvu.edu

‡elhamerfanian@mix.wvu.edu 


\section{Introduction}

Health care expenditures in the United States have been rising at a rate faster than any other country in the world (Sawyer and Cox (2018)). In 2015, health care expenditures accounted for $17.8 \%$ of the country's GDP (Centers for Medicare and Medicaid Services (2018)). However, higher health care expenditures do not necessarily lead to better health outcomes. Compared to most Organization for Economic Co-operation and Development (OECD) countries, the United States has a lower life expectancy, a higher obesity rate, a lower percentage of health insurance coverage, and below average numbers of doctors and hospital beds (Organization for Economic Co-operation and Development (2017)). This has led health economists and health care policymakers to explore what factors are causing increases in health care expenditures and to devise cost containment measures.

Since the 1970s, many studies have attempted to identify what factors impact health care expenditures. We categorize those factors into two groups: (1) non-environmental factors, and (2) environmental factors. Most of the literature that explores the determinants of health care expenditures focuses on non-environmental such as income, population age structure, inflation, number of practicing physicians, number of hospital beds, technological progress, and public financing of health care services among many others (Gerdtham and Jönsson (2000); Martin et al. (2011)). Published empirical works that have examined the impacts of environmental quality on health care expenditures are relatively rare. Available studies have used air quality as a proxy for environmental quality (Jerrett et al. (2003); Narayan and Narayan (2008); Qureshi et al. (2015); Yahaya et al. (2016); Zou et al. (2016)).

Environmental quality is an important factor that affects the health of individuals (World Health Organization (2018)). Poor air and/or water quality, in particular, can have adverse effects on human health (Hunter et al. (2010); Katsouyanni (2003)). For example, in the case of air pollution, it has been found that sulfur dioxide (SO2) causes changes in airway physiology (Chen et al. (2007)); carbon monoxide may cause pulmonary edema (Raub et al. (2000)); and particulate matter has been associated with cardiovascular diseases (Pope III and Dockery (2006)).

Water pollution can affect human health through exposures from direct consumption or recreational use. The main acute effects of drinking polluted water on health is gastrointestinal infections (Hunter et al. (2010)). In addition, chronic or acute exposure to different organic and inorganic chemicals in water can cause more severe health impacts including cancer, developmental or reproductive effects, neurological effects, and organ damage (U.S. Environmental Protection Agency. (2018a)).

Over the years, multiple laws have been enacted in the United States to ensure a healthsustaining rather than health-threatening environment. The Clean Air Act (CAA) of 1970, the Federal Water Pollution Control Act of 1948 (re-authorized as the Clean Water Act (CWA) in 1972), and the Safe Drinking Water Act (SDWA) of 1974 are few examples of federal environmental pollution laws passed to improve and protect the quality of air and water. Under these laws, the EPA establishes national environmental quality standards. States then have the option to apply for primacy and if accepted, they will be responsible for implementing and enforcing these laws. In addition, primacy states are able to set their own regulations to be stricter than the EPA's minimum requirements. Because of these laws, the United States has witnessed numerous improvements in terms of human health and environmental quality. For example, Sullivan et al. (2018) found that from 1970 to 1990 the CAA provided an estimated improvement of $\$ 22$ trillion in cumulative human health and reduced mortality benefits.

In terms of environmental quality, between 1970 and 2015, aggregate national emissions of six common air pollutants (particles, ozone, lead, carbon monoxide, nitrogen dioxide, and sulfur dioxide) dropped an average of $70 \%$ (U.S. Environmental Protection Agency. (2018b)). Moreover, before the 
SDWA, about $40 \%$ of public water systems failed to meet basic health standards, and now this value decreased to only 10\% (U.S. Environmental Protection Agency. (2014)). In 2015, about 21 million people living in the United States were served by public water systems that incurred violations of health-based quality standards of the SDWA (Allaire et al. (2018)). While not all violations cause immediate health problems, it has been estimated that contaminated drinking water is responsible for between 16.4 to 19.5 million cases of acute gastroenteritis every year in the United States (Duggal et al. (2015); Messner et al. (2006)).

Despite all of these efforts towards improving environmental quality as well as the significant progress in water treatment technology, multiple mid- and large-scale drinking water contamination episodes have been observed over the past few years (Duggal et al. (2015); Guilfoos et al. (2017)). One example is the Flint, Michigan crisis in 2014 where approximately 100,000 residents were exposed to high levels of lead from drinking water. Compared to other cities in Michigan, fertility rates decreased by $12 \%$, fetal death rates increased by $58 \%$, and overall health at birth decreased in Flint during the time of exposure (Grossman et al. (2017)). Another contamination incident occurred in 2014 in Charleston, West Virginia where chemical spills into the Elk River contaminated the drinking water for about 300,000 residents. This incident resulted in immediate and long-term health impacts. For the immediate health impacts, there were about 369 cases of acute gastrointestinal illness and 13 hospitalizations attributed to this contamination episode (Benedict et al. (2017)). For the long-term health impacts, Guilfoos et al. (2017)) estimated the causal effects of this incident on infant health outcomes and found a significant decrease in 5-minute Apgar Scores. Finally, another example is the Toledo, Ohio crisis in 2014 when toxic algae were found in the municipal drinking water affecting about 500,000 residents. This incident resulted in about 110 cases of acute gastrointestinal illness (Benedict et al. (2017)). Toledo spent an estimated $\$ 200,000$ per month to mitigate the effects of this event (Duggal et al. (2015)).

The exposure to contaminants in drinking water has been demonstrated to increase the consumption of health care services due to its deleterious impacts on human health and in turn, health care expenditures are bound to increase as well. For example, spending on medical care and water provisions in Flint amounted to about $\$ 60$ million in response to the 2014 water crisis (?). Furthermore, Naumova et al. (2016) estimated the costs of treating infections related to drinking contaminated water from 1991 to 2006 to be about $\$ 600$ million per year for Medicare beneficiaries alone. Given the existence of this relationship between drinking contaminated water and health care expenditures, this research examines the connection of drinking water quality to per capita health care expenditures.

In this paper, we examine the impact of drinking water contamination on per capita health care expenditures using U.S. state-level data from 2000 to 2011. We use the percentage of population served by public water systems that experienced violations of health-based standards in the SDWA as a proxy for drinking water contamination. The results show that there is a positive and statistically significant relationship between drinking water violations and state's per capita health care expenditures. Specifically, our results from a Spatial Durbin Model indicate that a 1\% decrease in the percentage of population that is exposed to drinking water quality violations is associated with in-state and regional reductions equal to $0.005 \%(\$ 0.32)$ and $0.035 \%(\$ 2.26)$ of per capita health care expenditures, respectively. The largest portion of these impacts are from adjacent states and not the state where the violation occurred. Air quality violations did not have a statistically significant impact on expenditures. This regional distribution of benefits from state level reductions in drinking water violation calls for greater regional cooperation in preventing contamination episodes. The results will help health policy makers to design efficient and effective health policy reforms.

The remainder of this paper is organized as follows. The rest of this section provides a background of the SDWA and a review of the literature examining the impact of environmental quality 
on health care expenditures. The following sections are data, the empirical model, and results describing the analytical framework and empirical results. Finally, the paper concludes with policy implications and research limitations plus future research.

\subsection{The Safe Drinking Water Act: Background}

The SDWA was initially passed in 1974 and then amended in 1986 and 1996. This act authorizes the U.S. EPA to regulate drinking water sources and infrastructure to protect public health by setting national health standards for drinking water against both naturally-occurring and man-made contaminants occurring in drinking water. Currently, the U.S. EPA has drinking water regulations for more than 90 contaminants. These standards apply to every one of the more than 150,000 active public water system in the United States (U.S. Environmental Protection Agency. (2013)).

The SDWA requires water systems to report their water quality periodically to the state primacy agency to make sure they meet the minimum requirements. The U.S. EPA has set different monitoring and sampling schedules for public water systems based on certain criteria such as population served, water source type, and historical monitoring data. For example, for microbial contaminants regulated under the total coliform rule (TCR), a public water system is required to take monthly samples based on its size as follows: 1 sample/month (very small), 2-3 samples/month (small), 4-10 samples (medium), 15-100 samples/month (large), and 120-480 samples/month (very large) (U.S. Environmental Protection Agency. (2010)). If a water system is collecting less than 40 samples/month and has more than one total coliform-positive sample, then the water system will be considered in violation to SDWA standards. On the other hand, if it is collecting 40 or more samples/month, and has more than $5 \%$ of the samples with total coliform-positive, then the system will be in violation of SDWA standards. Each quarter, the primacy agency then reports any violations of the SDWA to the U.S. EPA.

Violations to the SDWA standards are grouped into two main categories: (1) health-based violations, and (2) monitoring and communication with the public violations. Health-based violations include violations to the Maximum Contaminant Levels (MCLs), Maximum Residual Disinfectant Levels (MRDLs), and Treatment Techniques (TT) standards. MCL and MRDL set the highest level of a contaminant or a disinfectant residual that is allowed in drinking water without imposing any danger to the human health. If it is technically not possible to monitor a certain contaminant or not economically feasible to do so, a TT is used instead. For example, lead has no known safe levels and since it is impossible to monitor it under the MCL regulations, a TT is used, where any detection of lead may result in replacing some of the service lines to consumers.

Monitoring and communication with the public violations include violations to Monitoring and Reporting (MR) and other standards such as not sending the annual drinking water quality report to the customers. If a water system has a MR violation, this indicates that the system has failed in completing the regular testing requirements or failed to submit test results to the state primacy agency in the required time.

\subsection{Literature Review}

As mentioned in the introduction, previous research has focused on the relationship between health care expenditures and non-environmental factors, such as income and population age structure. Those studies have used different methodologies and models to explore these relationships. Previous research shows variable coefficient estimates with conflicting results. For example, some studies such as Wang (2009) and Thornton and Rice (2008) found that the number of beds has a positive impact on per capita health care expenditures, whereas others such as Prieto and Lago-Peñas (2012) and 
Reich et al. (2012) found the opposite impact. However, income has been found to consistently have a positive impact on health care expenditures (Baltagi and Moscone (2010); Holly et al. (2011)). Some researchers argue that the inconsistent findings from non-income factors can be attributed to differences in estimation methods used or the lack of a formal economic theory regarding the determinants of health care expenditures (Gerdtham and Jönsson (2000); Wilson (1999)).

Some older studies attempted to capture the effect of environmental quality by using urbanization as a proxy, which coincides with industrialization and, in turn, industrial pollution (Gbesemete and Gerdtham (1992); Gerdtham and Jönsson (2000); Kleiman (1974)). However, urbanization is highly correlated with income and other variables, and these studies found either insignificant coefficients or unexpected signs.

Jerrett et al. (2003) were among the first authors to investigate the direct relationship between health care expenditures and environmental indicators. They represented environmental indicators as total toxic pollution emissions in all environmental media and government environmental protection expenditures. Cross-sectional data from 49 counties in Ontario, Canada were employed in a sequential two-stage regression model to consider the endogenous relationship between health care expenditures and mortality. They found that counties with higher pollution emissions tend to have higher per capita health care expenditures, where a one-ton increase in emissions is associated with $\$ 0.03$ higher per capita health expenditures. Moreover, countries that spend more on improving environmental quality have lower per capita health care expenditures. It was estimated that a one dollar increase in defensive expenditures are associated with $\$ 0.31$ lower per capita health expenditures.

Narayan and Narayan (2008) examined the relationship between environmental quality and health care expenditures using data for eight OECD countries from 1980 to 1999. As a proxy for environmental quality, they used air emissions of sulfur oxide, nitrogen oxide, and carbon monoxide emissions. Furthermore, they undertook a panel cointegration approach to estimate both shortand long-run impacts of environmental quality on health care expenditures. They found that in the long-run, sulfur oxide and carbon monoxide emissions had statistically significant, positive impacts on per capita health care expenditures. For example, they estimated that a $1 \%$ increase in sulfur oxide emissions increases per capita health care expenditures by $0.04 \%$. In the short-run, carbon monoxide emissions were the only environmental quality indicator that had a statistically significant, positive impact on per capita health care expenditures. However, the magnitude of the impact was smaller than the long-run.

Using a panel cointegration approach similar to Narayan and Narayan (2008), other studies such as Qureshi et al. (2015), Yahaya et al. (2016), and Zou et al. (2016) have employed different datasets to examine the relationship between environmental quality, proxied by various indicators related to air pollution, and health care expenditures. Generally, the results from these studies indicate that in the long-run, air pollution has a statistically significant and positive impact on health care expenditures, but this estimated impact is smaller in the short-run.

Past studies that explored the relationship between environmental quality and health care expenditures have largely used air quality to proxy environmental quality. Thus, a possible extension to the literature is to use other proxies to environmental quality, such as drinking water quality, which is the objective of this paper.

\section{Data}

In this section, we provide background information and data sources for the variables used in the analysis. The empirical analysis is based on annual, state-level data for 48 contiguous U.S. states 
for the period 2000 to 2011.

\subsection{Dependent variable - Health care expenditures}

To measure health care expenditures, we use the per capita Personal Health Care (PHC) expenditures component of the National Health Expenditure Accounts (NHEA) estimates provided by the CMS. The NHEA comprise the official government estimates of aggregate health care spending in the U.S. These annual estimates are comprehensive since they encompass all the main elements of the health care system in a unified, mutually exclusive and exhaustive structure. These are multidimensional because they include information about expenditures on medical goods and services, and those who paid to finance these expenditures. A consistent methodology and classification system is used that employs a common set of definitions which allows comparisons between groups over time (Catlin and Cowan (2015):Centers for Medicare and Medicaid Services (2015b)).

The NHEA categorizes state health care spending data into two types: spending by state of provider and spending by state of residence. In the former, the estimates include all revenues obtained by health care providers in a state for supplying health care goods and services to both residents and non-residents. These estimates are used to measure the GDP of a state from the health care sector. In the latter, the estimates contain all health care expenditures by residents of a state whether the service is provided in or out of the state. These estimates are used to develop the per capita measures to compare between states.

To estimate health care expenditures by state, the CMS follows a multi-step process: (1) expenditures by state of provider (or the state where health care goods and services are consumed) are developed for each PHC service using provider-based survey data; (2) estimates of spending by payer (Medicare, Medicaid, and private health insurance) are developed using a combination of administrative claims data and survey data; and (3) the provider-based expenditures for each service and for Medicare are converted to a state of residence basis using information on health care expenditure patterns (or flows) between states. Expenditure estimates for Medicaid and for private health insurance are both assumed to be already on a state of residence basis. The aggregate values then are divided by the total state population to obtain the per capita PHC.

PHC is defined as total spending on health care goods and services minus administration and the net cost of private health insurance, government public health activities, and investment in research, structures, and equipment. Various goods and services are included in the PHC such as hospital care, physician and clinical services, dental services, and home health care. However, two types of health care spending are not included in the PHC due to the availability of the data: (1) health care expenditure estimates for health services provided to recipients outside the country that were paid for by Medicare, and (2) health care services obtained by individuals residing in United States territories who returned to the United States to receive them. According to Cuckler et al. (2011) those limitations do not affect the findings when using the per capita PHC data.

Since the values provided by the CMS are nominal, we use the Personal Health Care index to adjust for inflation, which according to Dunn et al. $(2018)$ is the most preferred index to use when adjusting total medical expenditures for inflation.

\subsection{Independent variables}

We group the independent variables into four categories based upon how they affect health care expenditures: drinking water quality, ability to pay, demand for health care services, and supply of health care services. 


\subsubsection{Drinking Water quality}

In this paper, we are interested in the impact of health-based violations for drinking water so our focus is limited to the population served by public water systems. The percentages of this population in each state that experience violations of the MCL or TT standards are used as a proxy for drinking water quality since MRDL violations rarely occur. Even if MRDL violations are used, they are too small to result in consistent outcomes (Wallsten and Kosec (2008)). We obtain the population served by those systems that experienced violations in each year from the U.S. EPA's Factoids: Drinking Water and Ground Water Statistics reports. We then divide the U.S. EPA estimates by each state's population to compute the percentage of the state population that has been exposed to health-based violations for drinking water each year.

\subsubsection{Ability to pay}

Income - One of the most important factors that drives health care expenditures is income. Previous studies that explored the determinants of health care expenditures at the international, national, and regional levels have all shown that an increase in income will result in an increase in health care expenditures (Murthy and Ukpolo (1994); Newhouse (1977); Wang (2009)). To control for this variable, we use real per capita state GDP as a proxy for income. These data were obtained from the United States Bureau of Economic Analysis (BEA).

Unemployment and uninsured rates - The impacts of unemployment and uninsured rates on health care expenditures are ambiguous. An increase in state's unemployment rate or uninsured rate could limit the ability to pay for health care goods and services, and therefore, health care expenditures would decrease. On the other hand, an increase in states' unemployment rate or uninsured rate could also increase per capita health care expenditures since while less people will be covered by private health insurance, more people will be covered by programs such as Medicaid. These two variables represent access to health care, which is an important determinant of health care expenditures. Data for these two variables were obtained from two different sources. The first is the Bureau of Labor Statistics (BLS), and the second is the Centers for Disease Control and Prevention (CDC) Behavioral Risk Factor Surveillance System (BRFSS) survey. To measure uninsured rate, the BRFSS asks the participants the following question: "Do you have any kind of health care coverage, including health insurance, prepaid plans such as HMOs, government plans such as Medicare, or Indian Health Service?" Each of these variables are measured as a percentage of the state population.

\subsubsection{Demand for health care services}

Health status - The health status of the state's residents will determine how much of health care goods and services will be consumed. To measure population health status, we use the health status variable from the BRFSS survey, where participants are asked, "How is your general health?", and respondents can choose among the provided answers (excellent, very good, good, fair, or poor). This measure is the percentage of population who have excellent health, therefore, we expect the coefficient to be negative since better health status will lead to less health care expenditures.

Population age structure - Another important determinant of health care expenditures is the state's population age structure. It is well observed that personal health care expenditures are unevenly distributed through a person life, with larger spending during older ages (Reinhardt (2003)). Therefore, we use the proportion of the state population who are enrolled in Medicare as measure of state's elderly population. According to Centers for Medicare and Medicaid Services (2015a), this measure has an advantage over the proportion of population over 65 years old because it is more 
closely related to state health spending. The data for this variable come from the CMS's Medicare Enrollment Dashboard. It is expected that an increase in this proportion will result in an increase in health care expenditures.

Environmental expenditures - Following Jerrett et al. (2003), we control for state's environmental expenditures to avoid the risk of omitted variable bias since it is expected that environmental expenditures may be correlated with the number of violations in a state. To measure this variable, we use state's spending on natural resources as a proxy similar to Fredriksson et al. (2011) and List and Sturm (2006). We use per square mile measures to account for size variation between states. It is expected that an increase in state's environmental expenditures will improve the state environmental quality and the overall public health, and therefore decrease health care expenditures. We obtain the data for this variable from the annual survey of state government finances from the Census Bureau.

Air quality - Following other studies that examined the impact of environmental quality on health care expenditures, we control for the impact of air quality by using the percentage of population that live in nonattainment areas (counties) that violate air quality standards. To compute this variable, we first obtain detailed information about those areas from the U.S. EPA's Green Book, which shows the status of each county in terms of attainment of nonattainment of the National Ambient Air Quality Standards (NAAQS). Then using population estimates from the Census Bureau we calculate the percentage of population affected by air pollution in each state. Since some states have no violations in some years, we transform this variable using $\log$ (air quality +0.001 )

\subsubsection{Supply of health care services}

The supply of health care services varies across the states. To account for this variation, we use the number of hospital beds per 1,000 population as an indicator for health care capacity in a state. As mentioned previously, the impact of this variable is ambiguous. In a competitive market environment, we would expect that a greater availability of health care services would lead to lower per capita health care expenditures, all other things being equal. However, it has been shown repeatedly in the literature that a greater supply of health care services may result in increased demand for health care services leading to higher health care spending. This positive impact is often explained as the supply-induced demand problem, where increasing competition leads health providers to recommend unnecessary services to maintain or increase their income (Frech (1996); ?). The data for this variable were obtained from the CDC's Health, United States reports.

\subsection{Descriptive statistics}

Table 1 provides summary statistics for the annual variables used in the analysis. The dependent variable is state level, real per capita health care expenditures. This variable ranges from $\$ 4,003$ in Utah to a maximum of $\$ 9,417$ in Massachusetts. Figure 1 illustrates the distribution of the average real per capita health care expenditures across the states between 2000 and 2011. Some of the highest levels of per capita health expenditures are observed in the Northeast and Mid-Atlantic regions, whereas some of the lowest levels are observed in the Southwest and Southeast regions. In a similar manner to per capita health care expenditures, Massachusetts is also the state with the highest percentage of population served by public water systems that violated the health-based standards with $78.56 \%$ of its population affected (Table 1). The statistical values for the other variables vary widely across the states over the analysis period. Real per square mile environmental expenditure varies from $\$ 910$ for Nevada to $\$ 74,070$ for New Jersey. Real per capita GDP also covers a large range, from $\$ 29,730$ to $\$ 86,200$, with Mississippi and Idaho having the lowest values 
Table 1: Summary statistics of annual, state-level data for the contiguous 48 states, 2000 to 2011

\begin{tabular}{|c|c|c|c|c|c|}
\hline Variable & Unit & Mean & St0. Dev.d & Min & Max \\
\hline Health care expenditures & 2009 dollars & $6,451.47$ & 973.48 & $4,003.96$ & 9,417 \\
\hline Drinking water quality & $\%$ & 7.33 & 7.72 & 0.01 & 78.56 \\
\hline Air quality & $\%$ & 39.97 & 36.98 & 0 & 100 \\
\hline Income & Thousand 2009 dollars & 48.94 & 9.25 & 29.73 & 86.20 \\
\hline Environmental expenditures per sq/mi & Thousand 2009 dollars & 10.56 & 12.21 & 0.91 & 74.07 \\
\hline Medicare enrollment & $\%$ & 14.88 & 1.98 & 9.18 & 20.81 \\
\hline Health status & $\%$ & 20.90 & 2.78 & 13.40 & 28.80 \\
\hline Number of hospital beds & Numbers & 2.95 & 0.90 & 1.70 & 6.10 \\
\hline Uninsured rate & $\%$ & 14.80 & 4.30 & 4.30 & 29.80 \\
\hline Unemployment rate & $\%$ & 5.73 & 2.12 & 2.30 & 13.70 \\
\hline
\end{tabular}

and Delaware and Connecticut having the highest values. The percentage of the population with excellent health ranges from $13.40 \%$ to $28.80 \%$ across the states, where the lowest value is for West Virginia and the highest is for Connecticut.

\section{Empirical Model}

We estimate two sets of models: non-spatial and spatial. First, we use variations of state level fixed effects (FE) and random effects (RE) models motivated by Reich et al. (2012), Cantarero and Lago-Peñas (2010), and Crivelli et al. (2006). Five models are estimated: (1) pooled OLS, (2) state fixed effects (FE), (3) random effects (RE), (4) state FE with year fixed effects, and (5) RE with year fixed effects. Results from the Hausman (1978) specification test indicate that the FE model is more appropriate than the random effects model. However, since our sample for most variables does not vary much over time, FE methods can lead to imprecise estimates (?). Furthermore, ? show that Hausman (1978) test is not appropriate when some or all of the explanatory variables have little within variable variation. Therefore, we present the results from both models and compare them.

It follows from the model description above that:

$$
y_{i t}=x_{i t} \beta+\alpha_{i}+\lambda_{t}+\epsilon_{i t}, \quad i=1, \ldots, N \quad t=1, \ldots, T
$$

where $y$ is the state's per capita health care expenditures, $x$ is $\mathrm{K} \times 1$ and contains our variable of interest and other control variables, $a$ is the state's fixed or random effect to account for the unobservable characteristics, $\lambda$ is the time fixed effect, and $\epsilon$ is the error term. Based on the epidemiological evidence found in many studies (see Villanueva et al. (2014)), we hypothesize a positive association such that an increase in state level drinking water violations will result in an increase in state level per capita health care expenditures.

In addition to using basic panel estimation methods, LeSage and Pace (2009) and Elhorst (2014) state that use of a general non-spatial estimation is based upon observed values being independent of location when there is no correlation between neighbors. In other words, in a non-spatial model, each observation has a mean of and a random component. The observation $i$ represents a region or point in space, which is considered to be independent of its neighboring regions or points $j$, i.e., $E\left(\epsilon_{i} \epsilon_{j}\right)=E\left(\epsilon_{i}\right) E\left(\epsilon_{j}\right)$ 


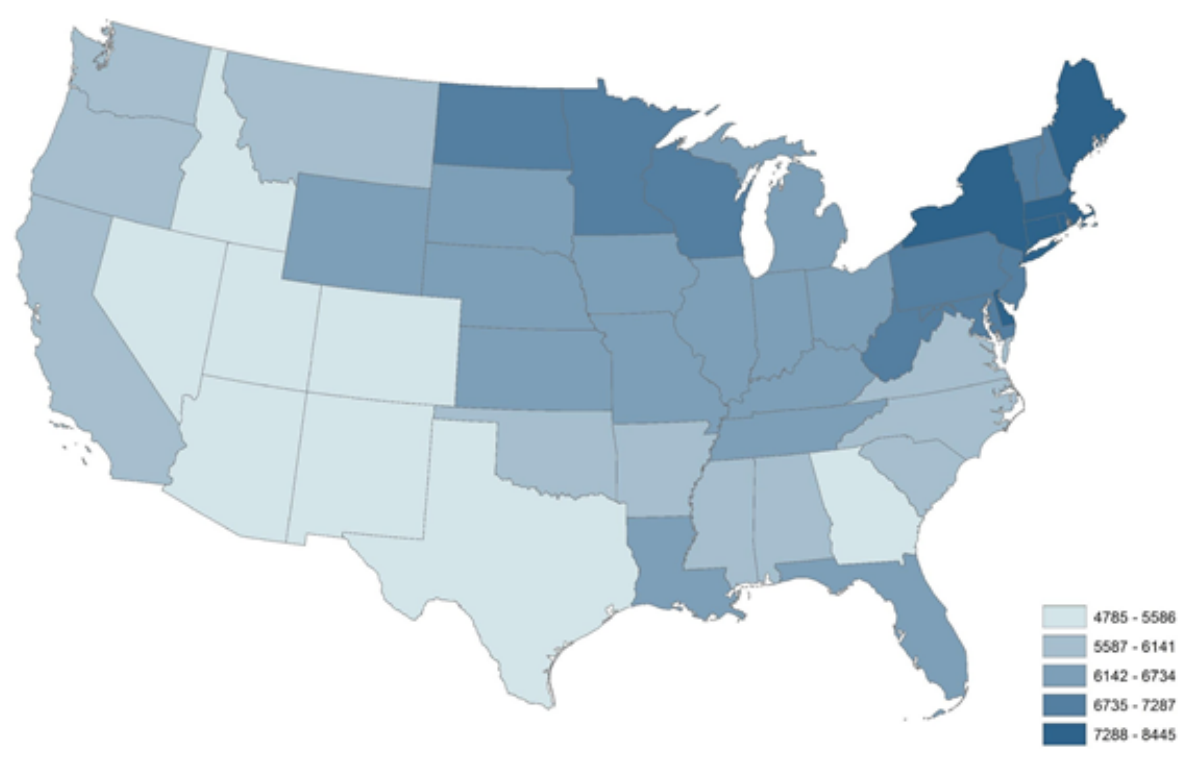

Figure 1: Average real per capita health care expenditures between 2000 and 2011 (\$2009)

However, in many cases, the assumption of observations' independency is not applicable. In other words, observations at different points or regions are dependent (LeSage and Pace (2009)). Pollution levels and health outcomes are examples of such a dependency assumption between the variable of interest and an outcome. For example, the pollution levels in region i may influence health outcomes in a neighboring region j (Chen et al. (2017); Erfanian and Collins (2019)). With spatial interdependence, we suppose two neighbors (regions) $i$ and $j$ which are spatially correlated with normality being assumed for the error terms:

$$
\begin{aligned}
& y_{i}=\rho_{i} y_{j}+x_{i} \beta+\epsilon_{i} \\
& y_{j}=\rho_{j} y_{i}+x_{j} \beta+\epsilon_{j}
\end{aligned}
$$

where the dependent variable in neighbor $j$ influences the dependent variable in neighbor $i$ and the reverse also holds true. Once a spatial component (whether this component is from the dependent variable, control variables, or the error term) is found to be statistically significant, then any coefficients estimated by a non-spatial model may be biased. In addition, by applying a non-spatial model when the spatial component is significant, variances may be non-efficient (Griffith (2013); LeSage and Pace (2009)). Accordingly, statistical tests (t-test and F-test) may be invalid, leading economists to interpret their results improperly.

Given that state level real per capita health expenditures show visual evidence of clustering (Figure 1), we test for spatial autocorrelation among states with a Moran's I. The global Moran's I is statistically significant (Moran's I index for $2000=0.16$, P-value $=0.02$; Moran's I index for $2011=0.21, \mathrm{P}$-value $=0.004)$ demonstrating that spatial interrelationships exist for health care expenditures and the need to apply spatial econometrics modeling. We also report the scatter plot of Moran's I to be sure that the positive spatial correlation for some observations and negative spatial correlation for other observations do not cancel out each other. Figure 2 provides the results. This figure illustrates that both at the start and end of the data, most of the states with high real per capita healthcare expenditures are adjacent to states with high real per capita health care 
expenditures. This also is true for the states with low real per capita health care expenditures. Thus, we have ample evidence to apply a spatial econometrics model in our analysis.

There are five possible spatial models. The first is a Spatial Autoregressive (SAR) Lag Model as shown in equations (2) and (3). A Spatial Error Model (SEM) has dependency in the error term, while a SLX model (Spatial Lag of Explanatory variables) assumes that only explanatory variables play a direct role in determining dependent variables. A Spatial Durbin Model (SDM) includes spatial lags of explanatory variables as well as the dependent variable, while a Spatial Error Durbin Model (SDEM) includes these lags along with spatially dependent disturbances.

To observe dependence between neighboring observations, spatial econometric models differentiate between direct and indirect effects. Direct effects show how changes in a variable for the $i^{\text {th }}$ state influences the $i^{\text {th }}$ state's dependent variable (in-state impacts). Indirect effects explain the effects of a variable in $j^{\text {th }}$ state on $i^{\text {th }}$ state's dependent variable (regional impacts). LeSage and Pace (2009) discusses that since the impacts of a variable are different among observations, it is desirable to have a measurement of overall and average impacts. Thus, these measurements are divided into the concepts of average direct, indirect, and total effects (LeSage and Pace (2014)).

Parameters in a general linear regression are interpreted as a partial derivative of the dependent variable with respect to the explanatory variable. An assumption of independency between observations serves as the basis for this interpretation. In a spatial model, however, interpretation of the parameters becomes more complicated. As numerous economists (Anselin and Le Gallo (2006); Kelejian et al. (2006); Kim et al. (2003); Le Gallo et al. (2003); LeSage and Pace (2009)) claim, a model with a spatial lag of the dependent variable requires special interpretation of the parameters. Elhorst (2014) calculated the direct, indirect and the total effect in a general nesting spatial model as

$$
Y=(I-\delta W)^{-1}(X \beta+W X \theta)+R
$$

where $W$ is the spatial weight matrix, $\delta$ is called the spatial autoregressive coefficient, $\theta$ represents a $K \times 1$ vector of fixed but unknown parameters to be estimated, and $R$ represents the intercept and error terms.

The matrix of partial derivatives of the expected dependent variable with respect to changes in explanatory variables becomes:

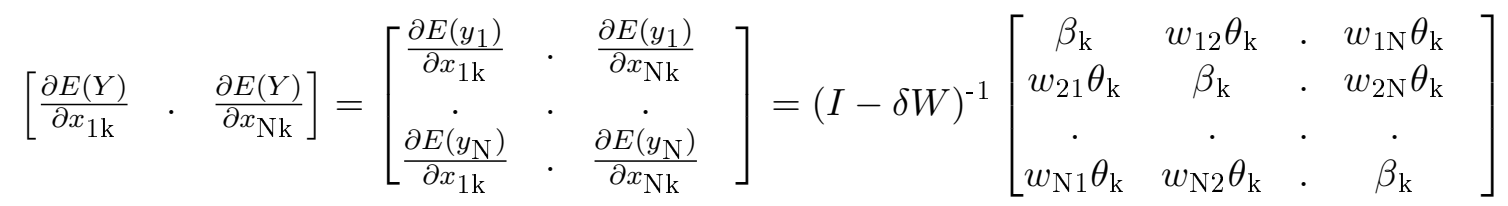

where $w_{\mathrm{ij}}$ is the $(i, j)^{\mathrm{th}}$ element of $W$. Every diagonal element of the partial derivative matrix in equation (5) shows the direct effect while the indirect effects are shown by every off-diagonal element. Since the direct and indirect effects are unique for each observation, LeSage and Pace (2009) suggest reporting the summary indicators (the average of the diagonal elements for the direct effect and the average of either the row sums or the column sums of the off-diagonal elements for indirect effects). Since $\theta$ in a SAR model is equal to zero, indirect effect would be equal to the off-diagonal elements of $(1-\delta \mathrm{W})^{-1} \beta_{k}$.

The weight matrix $\mathrm{W}$ describes the interrelationships between observations. According to Elhorst (2014), the weight matrix can be thought of as a tool to define the neighbors for any given region. This definition can be in a geographical dimension or in another framework such as the share of trade or transportation. Various units of measurement for spatial dependencies such as 

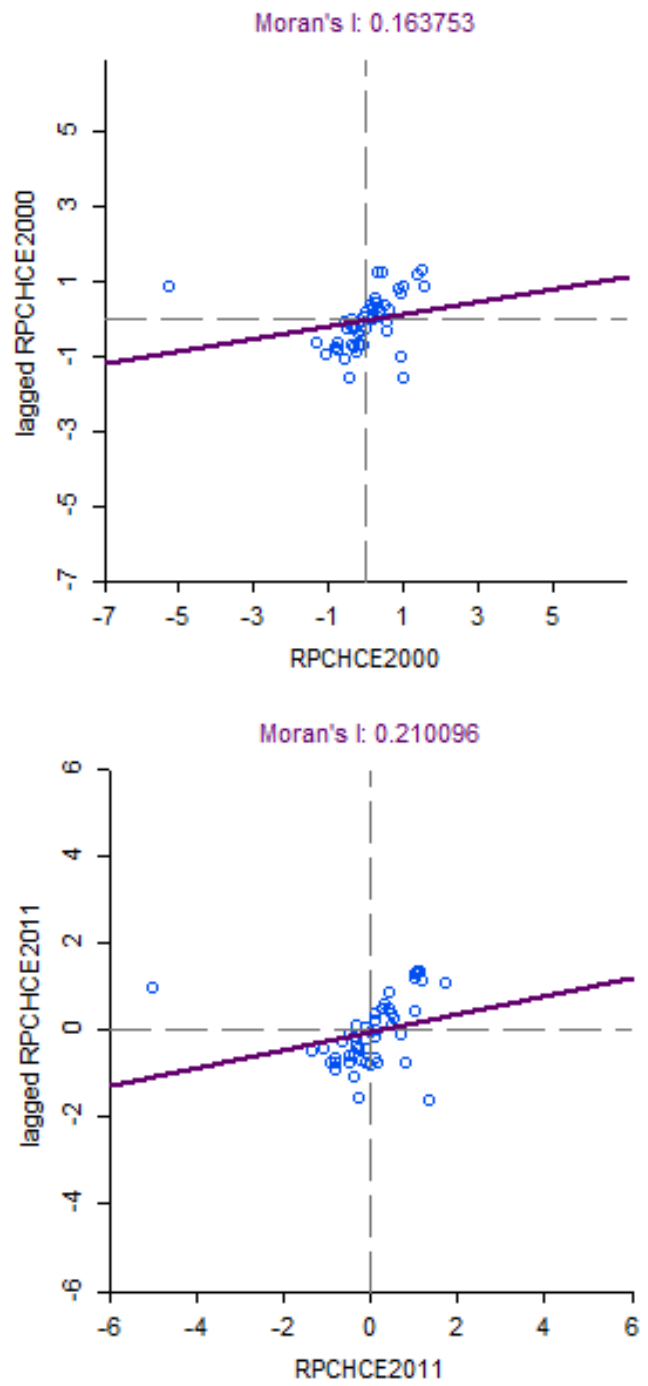

Figure 2: Scatter plots of Moran's I for 2000 and 2011 
cities, counties, states, and countries are available for spatial analysis (Getis (2007)). Our spatial weight matrix is based on the distance between the center of states and we applied a three nearestneighbors weight matrix. We tested between SDM and SDEM model by using a Bayesian posterior probability model and the result confirmed that the most appropriate model to capture the spillover effect for our model is the SDM model. Spatial econometric models are estimated using Matlab software codes provided by Dr. Donald Lacombe.

Following previous studies in the determinants of health care expenditures literature, all variables are measured in logarithmic form, so the regression coefficients are interpreted as elasticity estimates. Moreover, we evaluate the data using the extended projection (PE) test from MacKinnon et al. (1983) to compare the log-log and linear specifications, and the results indicate that the log-log model is more appropriate. With the SDM, we estimate the marginal effects (direct, indirect, and total) of the independent variables on per capita health care expenditures using the original data from 2000-2011.

\section{Results}

Table 2 reports the regression results for the non-spatial models. In most models, our estimates for drinking water quality violations are positive and statistically significant, but they become insignificant when we include time fixed effects. In terms of the expected signs for the other explanatory variables, $\mathrm{RE}$ model coefficient estimates are similar to those for the $\mathrm{FE}$ models. However, $\mathrm{RE}$ models show some improvement in terms of the statistical significance of the estimates, which is expected since the FE models are not suitable in this case due to the low within variation in the data (Cameron and Trivedi (2010); Clark and Linzer (2015)). Therefore, we choose the RE model as the preferred non-spatial model.

Overall, the results show that drinking water quality has a relatively small impact on per capita health care expenditures. Using the coefficient estimates from the RE model (4) in Table 2, the results show that a $1 \%$ decrease in the population served by public water systems that experience violations in SDWA's health-based standards, on average, would decrease annual per capita health care expenditures by $0.009 \%$, all else being equal. Based on the average per capita health care expenditures reported in Table 1 , this percentage totals to about $\$ 0.58$ per person annually. Comparing this to other variables with larger coefficient estimates, such as Medicare enrollment, where a $1 \%$ increase would result in an increase in per capita health care expenditures by $1.130 \%$ (about $\$ 72.84$ per person annually) shows how small the impact is for drinking water quality violations on per capita health care expenditures.

Table 3 reports the results of the direct, indirect, and total effects from the Spatial Durbin Model (SDM) with RE and year fixed effects. The coefficient of spatially lagged dependent variable is 0.149 and statistically significant at a $1 \%$ level, which indicates that the results from Table 2 are likely biased. This result also reveals that state level per capita health care expenditures tend to increase in response to higher per capita health care spending in neighboring states. This is expected since state level health care expenditures and health policy decisions depend on the surrounding states (Bose et al. (2015)). Therefore, this prior research suggests that per capita health care expenditures follow the same path as state level health care expenditures.

With respect to the drinking water quality variable, the results show that this variable has a positive and statistically significant impact on per capita health care expenditures both within the state itself as well as in neighboring states. Relative to the direct effect, the magnitude of the average indirect effect of drinking water quality violations in state i is fairly large. Specifically, a $1 \%$ decrease

in the population served by public water systems that experience violations of SDWA's health-based 
standards in state i, on average, would decrease annual per capita health care expenditures by $0.005 \%$ $(\$ 0.32)$ in state i, and by $0.035 \%(\$ 2.26)$ in its three neighboring states.

To illustrate the extent of this decrease on a state's total health care expenditures, we choose the state of Oklahoma. This state has one of the highest percentages of population exposed to violations. We calculate the decrease in total health care expenditures resulting from a $1 \%$ decrease in the population experiencing violations in drinking water quality. We obtain this value by multiplying $\$ 0.32$ by Oklahoma's 2011 population. Therefore, a 1\% decrease in the population exposed to drinking water quality violations would result in an estimated $\$ 1.2$ million decrease in annual health care expenditures within the state of Oklahoma. For Oklahoma's three nearest neighbors (Texas, Arkansas, and Kansas), however, this $1 \%$ reduction would, on average, result in about a $\$ 71.1$ million reduction in annual health care expenditures. Further, we examine the in-state and regional impacts of a $1 \%$ reduction across all 48 contiguous states. Multiplying the dollar values by the 2011 state populations, we find that, on average, this will lead to $\$ 98.9$ million and $\$ 698.2$ million reductions in annual health care expenditures for in-state and regional impacts, respectively.

The public water system costs to achieve a $1 \%$ reduction in the number of violations across all 48 states are uncertain. These costs will be largely passed on to the water system's customers and will depend on many factors such as system size and type of contaminant. According to Auerbach (1994), cost increases to comply with SDWA standards range from $2 \%$ of water charges for households served by large public water systems to $55 \%$ for households served by small systems. A more recent estimate of the costs associated with compliance to SDWA standards over the next 20 years is provided by the USEPA's (?) Drinking Water Infrastructure Needs Survey and Assessment. The U.S. EPA estimates that out of total national needs ( $\$ 472.6$ billion), about $12 \%$ ( $\$ 57$ billion) is related to violations of SDWA regulations. It is unclear how much of this $\$ 57$ billion would be required to achieve a $1 \%$ reduction.

For the other control variables, the direct effect of income is positive and statistically significant as expected. Our estimates, however, are less than the estimates found in other studies such as Wang (2009) and Bose (2015)). For access to health care variables, the unemployment rate is statistically insignificant in all effects. The indirect effect of uninsured rate is positive and statistically significant, which indicates that an increase in the uninsured rate in state $\mathrm{i}$ will result in an increase in per capita health care expenditures in neighboring states.

Examining the demand for health care services variables, the health status variable has a statistically significant, negative direct effect as expected. Medicare enrollment, similar to CMS (Centers for Medicare and Medicaid Services (2015a)), is positive and statistically significant for both the direct and indirect effects so that increases in Medicare enrollment not only increases in state, but also the neighboring three states' per capita health care expenditures. This variable has the largest impact of any variable on per capita health care expenditures in our model. This impact is expected since per capita health expenditures for people age 65 or older, on average, are three to five times higher than spending by young people (Reinhardt (2003)). Finally, environmental expenditures per square mile have positive and statistically significant direct effects on health care expenditures. This result indicates that higher expenditures reflect the existence of more environmental problems, leading to higher per capita health care expenditures due to the population facing more health risks related to environmental quality. The air quality variable has an unexpected negative impact, but it is not statistically different from zero.

For the supply of health care variable, only the indirect effect for number of hospital beds is negative and statistically significant. A possible explanation for this result is that hospitals in state i compete with hospitals in neighboring states by improving quality of the services, and therefore, lower the cost of health care for patients from neighboring states (Bose et al. (2015)). Thus, a higher supply of health care services benefits consumers in neighboring states by reducing their per capita 
health care expenditures rather than in the state where more hospital beds are provided.

Table 2: Non-spatial regression results, dependent variable of annual, state level per capita health care expenditures

\begin{tabular}{|c|c|c|c|c|c|}
\hline & $\begin{array}{c}(1) \\
\text { Pooled }\end{array}$ & $\begin{array}{l}(2) \\
\mathrm{FE}\end{array}$ & $\begin{array}{l}(3) \\
\text { FE }\end{array}$ & $\begin{array}{l}(4) \\
\mathrm{RE}\end{array}$ & $\begin{array}{l}(5) \\
\mathrm{RE}\end{array}$ \\
\hline Drinking water quality & $\begin{array}{c}0.016^{* * *} \\
(0.000)\end{array}$ & $\begin{array}{c}0.008^{*} \\
(0.055)\end{array}$ & $\begin{array}{c}0.000 \\
(0.910)\end{array}$ & $\begin{array}{c}0.009^{* *} \\
(0.026)\end{array}$ & $\begin{array}{c}0.001 \\
(0.705)\end{array}$ \\
\hline Air quality & $\begin{array}{c}0.000 \\
(0.938)\end{array}$ & $\begin{array}{l}-0.001 \\
(0.526)\end{array}$ & $\begin{array}{l}-0.001 \\
(0.176)\end{array}$ & $\begin{array}{l}-0.001 \\
(0.688)\end{array}$ & $\begin{array}{l}-0.001 \\
(0.432)\end{array}$ \\
\hline Income & $\begin{array}{c}0.323^{* * *} \\
(0.000)\end{array}$ & $\begin{array}{c}0.058 \\
(0.596)\end{array}$ & $\begin{array}{c}0.271^{* * *} \\
(0.000)\end{array}$ & $\begin{array}{c}0.212^{* *} \\
(0.017)\end{array}$ & $\begin{array}{c}0.305^{* * *} \\
(0.000)\end{array}$ \\
\hline Environmental expenditures & $\begin{array}{c}0.015^{* * *} \\
(0.005)\end{array}$ & $\begin{array}{l}0.047^{*} \\
(0.073)\end{array}$ & $\begin{array}{c}0.008 \\
(0.481)\end{array}$ & $\begin{array}{c}0.021 \\
(0.165)\end{array}$ & $\begin{array}{c}0.018^{* *} \\
(0.043)\end{array}$ \\
\hline Medicare enrollment & $\begin{array}{c}0.721^{* * *} \\
(0.000)\end{array}$ & $\begin{array}{c}1.212^{* * *} \\
(0.000)\end{array}$ & $\begin{array}{c}0.443^{* * *} \\
(0.007)\end{array}$ & $\begin{array}{c}1.130^{* * *} \\
(0.000)\end{array}$ & $\begin{array}{c}0.521^{* * *} \\
(0.000)\end{array}$ \\
\hline Health status & $\begin{array}{l}-0.038 \\
(0.281)\end{array}$ & $\begin{array}{c}-0.168^{* * *} \\
(0.001)\end{array}$ & $\begin{array}{c}-0.042^{* *} \\
(0.050)\end{array}$ & $\begin{array}{c}-0.214^{* * *} \\
(0.000)\end{array}$ & $\begin{array}{c}-0.031 \\
(0.134)\end{array}$ \\
\hline Number of hospital beds & $\begin{array}{l}-0.018 \\
(0.305)\end{array}$ & $\begin{array}{c}-0.463^{* * *} \\
(0.000)\end{array}$ & $\begin{array}{c}0.077 \\
(0.109)\end{array}$ & $\begin{array}{c}-0.262^{* * *} \\
(0.000)\end{array}$ & $\begin{array}{c}0.061^{*} \\
(0.055)\end{array}$ \\
\hline Uninsured rate & $\begin{array}{c}-0.114^{* * * *} \\
(0.000)\end{array}$ & $\begin{array}{c}0.004 \\
(0.885)\end{array}$ & $\begin{array}{c}-0.043 * * * \\
(0.001)\end{array}$ & $\begin{array}{l}-0.028 \\
(0.374)\end{array}$ & $\begin{array}{c}-0.052^{* * *} \\
(0.000)\end{array}$ \\
\hline Unemployment rate & $\begin{array}{c}0.107 * * * \\
(0.000)\end{array}$ & $\begin{array}{c}0.009 \\
(0.526)\end{array}$ & $\begin{array}{c}-0.001 \\
(0.902)\end{array}$ & $\begin{array}{c}0.052^{* * *} \\
(0.000)\end{array}$ & $\begin{array}{c}0.006 \\
(0.545)\end{array}$ \\
\hline Constant & $\begin{array}{c}3.515^{* * *} \\
(0.000)\end{array}$ & $\begin{array}{c}5.448^{* * *} \\
(0.001)\end{array}$ & $\begin{array}{c}4.563^{* * *} \\
(0.000)\end{array}$ & $\begin{array}{c}4.177^{* * *} \\
(0.000)\end{array}$ & $\begin{array}{c}3.895^{* * *} \\
(0.000)\end{array}$ \\
\hline Year fixed effect & No & No & Yes & No & Yes \\
\hline Adjusted R-squared & 0.662 & 0.754 & 0.959 & 0.516 & 0.868 \\
\hline Number of observations & 576 & 576 & 576 & 576 & 576 \\
\hline
\end{tabular}

Numbers in the parentheses represent p-values

$*, * *$, and $* * *$ refer to $10 \% 5 \%$, and $1 \%$ significance levels, respectively.

\section{Conclusions}

In this paper, we estimate the impact of drinking water quality violations on state level per capita health care expenditures using a proxy variable of the percentage of population served by public water systems that experienced violations of SDWA's health-based standards. We estimate both spatial and non-spatial models and control for factors that the reflect air pollution as well as ability to pay plus demand for and supply of health care services. Data from 48 contiguous states for the period 2000 to 2011 are used.

We find a positive and statistically significant relationship between drinking water quality violations and state level per capita health care expenditures. Specifically, the results from the Spatial Durbin Model indicate that a $1 \%$ decrease in the percentage of population exposed to violations is associated with reductions in direct and indirect effects equal to $0.005 \%(\$ 0.32)$ and $0.035 \%$ (\$2.26) of per capita health care expenditures. The large difference between the direct (in-state) and indirect (regional) effects is unexpected. One possible explanation for this difference is that drinking water violations are indicative of broader water source contamination problems that cross state lines, such as extreme weather events (Curriero et al. (2001)). Such an explanation warrants a more coordinated regional approach across states when addressing water quality problems related to 
Table 3: Spatial Durbin model with random effects regression results, dependent variable of annual, state level per capita health care expenditures

\begin{tabular}{lccc}
\hline \hline & $(1)$ & $(2)$ & $(3)$ \\
& Direct effect & Indirect effect & Total effect \\
\hline Drinking water quality & $0.005^{* * *}$ & $0.035^{* * *}$ & $0.040^{* * *}$ \\
Air pollution & $(0.008)$ & $(0.003)$ & $(0.003)$ \\
Income & -0.002 & -0.002 & -0.004 \\
& $(0.379)$ & $(0.850)$ & $(0.755)$ \\
Environmental expenditures & $0.253^{* * *}$ & 0.078 & $0.331^{* * *}$ \\
& $(0.000)$ & $(0.209)$ & $(0.000)$ \\
Medicare enrollment & $0.013^{* *}$ & -0.018 & -0.005 \\
& $(0.028)$ & $(0.518)$ & $(0.882)$ \\
Health status & $0.606^{* * *}$ & $1.374^{* * *}$ & $1.979^{* * *}$ \\
Number of hospital beds & $(0.000)$ & $(0.000)$ & $(0.000)$ \\
& $-0.053^{* *}$ & 0.125 & 0.072 \\
Uninsured rate & $(0.019)$ & $(0.296)$ & $(0.598)$ \\
Unemployment rate & -0.001 & $-0.438^{* * *}$ & $-0.439^{* * *}$ \\
& $(0.953)$ & $(0.000)$ & $(0.000)$ \\
\hline Rho & -0.010 & $0.126^{* *}$ & $0.116^{* *}$ \\
& $(0.379)$ & $(0.014)$ & $(0.048)$ \\
\hline Year fixed effect & 0.001 & -0.018 & -0.017 \\
Adjusted R-squared & $(0.875)$ & $(0.460)$ & $(0.533)$ \\
\hline Number of observations & & $0.149^{* * *}$ & \\
\hline \hline & & $(0.000)$ & \\
\hline
\end{tabular}

Numbers in the parentheses represent p-values

$*, * *$, and $* * *$ refer to $10 \% 5 \%$, and $1 \%$ significance levels, respectively. 
drinking water quality violations as is practiced by entities such as river basin commissions Abdalla et al. (2010)).

Our estimate of reductions in per capita health expenditures stemming from lowering drinking water quality violations is just one benefit that arises from drinking water quality improvement. Another more localized benefit includes real estate value impacts from correcting source water contamination problems. Examples of research include Liu et al. (2017)), Tuttle and Heintzelman (2015), and Leggett and Bockstael (2000). Given the high investment costs associated with lowering of drinking water quality violations, a full accounting of all benefits from these reductions will be needed to offset these costs.

Furthermore, we find that drinking water quality violations have a larger impact on health care expenditures than air quality violations, which have a statistically insignificant impact. This result is different than what other studies have found when examining the impact of air quality on health care expenditures (examples include Narayan and Narayan (2008) and Yahaya et al. (2016). Our result shows that when exposure to environmental contamination is measured as violation of a standard or not and aggregated across multiple pollutants, then exposure to drinking water quality violations has a larger impact on health care expenditures than exposure to air quality violations.

Limitations of this research relate primarily to the data that are used. Our data only covers public water systems, thereby excluding about 45 million people who use private wells for their drinking water, which are not regulated under the SDWA (U.S. Geological Survey $(2009)$ ). Considering this population in future research would expand results to consider the implications of drinking water violations to more rural areas. Moreover, the proxy variable that we used to reflect exposure to drinking water contamination has its flaws. These data include multiple types of contaminants that affect human health differently (i.e. short- and long-run health impacts). Due to a lack of knowledge, we did not include a lag system for population exposure to drinking water violations in our model to account for a range of temporal health impacts from contaminant exposures. Finally, water systems have financial incentives not to comply with all the U.S. EPA regulations due to the higher costs that it will impose on these systems (Bennear et al. 2009). Therefore, there is a higher probability that false or missing data are being reported. For example, the agency estimated that states were not reporting $40 \%$ of all health-based violations (U.S. Environmental Protection Agency. (2004)). Employing these changes in the drinking water quality variable may yield different results from our current models. 


\section{References}

Abdalla, C., Drohan, J., and Becker, J. (2010). River Basin Approaches to Water Management in the Mid-Atlantic States. Penn State College of Agricultural Sciences, Cooperative Extension.

Allaire, M., Wu, H., and Lall, U. (2018). National Trends in Drinking Water Quality Violations. Proceedings of the National Academy of Sciences, 115(9):2078-2083.

Anselin, L. and Le Gallo, J. (2006). Interpolation of Air Quality Measures in Hedonic House Price Models: Spatial Aspects. Spatial Economic Analysis, 1(1):31-52.

Auerbach, J. (1994). Costs and Benefits of Current sdwa Regulations. Journal-American Water Works Association, 86(2):69-78.

Baltagi, B. H. and Moscone, F. (2010). Health Care Eexpenditure and Income in the oecd Reconsidered: Evidence from Panel Data. Economic modelling, 27(4):804-811.

Benedict, K. M., Reses, H., Vigar, M., Roth, D. M., Roberts, V. A., Mattioli, M., Cooley, L. A., Hilborn, E. D., Wade, T. J., Fullerton, K. E., et al. (2017). Surveillance for Waterborne Disease Outbreaks Associated with Drinking Water-United States, 2013-2014. MMWR. Morbidity and mortality weekly report, 66(44):1216.

Bose, S. (2015). Determinants of Per Capita State-Level Health Expenditures in the United States: A Spatial Panel Approach. Journal of Regional Analysis and Policy, Forthcoming, 45(1):93-107.

Bose, S., Gebremedhin, T., and Sambamoorthi, U. (2015). State-Level Variations in Hospital Expenditures: An Application of Spatial Regression. Journal of Health Care Finance, 42(1).

Cameron, A. C. and Trivedi, P. K. (2010). Microeconometrics Using Stata, volume 2. Stata press College Station, TX.

Cantarero, D. and Lago-Peñas, S. (2010). The Determinants of Health Care Expenditure: A Reexamination. Applied Economics Letters, 17(7):723-726.

Catlin, A. C. and Cowan, C. A. (2015). History of Health Spending in the United States, 1960-2013. Baltimore, MD: Centers for Medicare and Medicaid Services.

Centers for Medicare and Medicaid Services (2015a). Econometric Analysis of State Health Expenditures: Methodology and Model Specification. https://www.cms.gov/Research-Statistics-Dataand-Systems/Statistics-Trends-and-Reports/NationalHealthExpendData/Downloads/StateModel-14.pdf. Accessed on 01/24/2018.

Centers for Medicare and Medicaid Services (2015b). National Health Expenditure Accounts: Methodology Paper, 2015. https://www.cms.gov/NationalHealthExpendData/. Accessed on $02 / 20 / 2018$.

Centers for Medicare and Medicaid Services (2018). Historical National Health Expenditure Data. https://www.cms.gov/Research-Statistics-Data-and-Systems/Statistics-Trends-andReports/NationalHealthExpendData/index.html. Accessed on 08/20/2018.

Chen, T.-M., Kuschner, W. G., Gokhale, J., and Shofer, S. (2007). Outdoor Air Pollution: Nitrogen Dioxide, Sulfur Dioxide, and Carbon Monoxide Health Effects. The American journal of the medical sciences, 333(4):249-256. 
Chen, X., Shao, S., Tian, Z., Xie, Z., and Yin, P. (2017). Impacts of Air Pollution and Its Spatial Spillover Effect on Public Health Based on China's Big Data Sample. Journal of cleaner production, 142:915-925.

Clark, T. S. and Linzer, D. A. (2015). Should I Use Fixed or Random Effects? Political Science Research and Methods, 3(2):399-408.

Crivelli, L., Filippini, M., and Mosca, I. (2006). Federalism and Regional Health Care Expenditures: An Empirical Analysis for the Swiss Cantons. Health Economics, 15(5):535-541.

Cuckler, G., Martin, A., Whittle, L., Heffler, S., Sisko, A., Lassman, D., and Benson, J. (2011). Health Spending by State of Residence, 1991-2009. Medicare \& Medicaid Research Review, 1(4).

Curriero, F. C., Patz, J. A., Rose, J. B., and Lele, S. (2001). The Association Between Extreme Precipitation and Waterborne Disease Outbreaks in the United States, 1948-1994. American journal of public health, 91(8):1194-1199.

Duggal et al. (2015). A Public Health Legal Guide to Safe Drinking Water. http://www.astho.org/Public-Policy/Public-Health-Law/Public-Health-Authority-Over-

Drinking-Water-Quality-Overview/. Accessed on 05/09/2018.

Dunn, A., Grosse, S. D., and Zuvekas, S. H. (2018). Adjusting Health Expenditures for Inflation: a Review of Measures for Health Services Research in the United States. Health services research, $53(1): 175-196$.

Elhorst, J. P. (2014). Spatial Econometrics: from Cross-Sectional Data to Spatial Panels, volume 479. Springer.

Erfanian, E. and Collins, A. R. (2019). Air Quality and Asthma Hospitalization: Evidence of PM2.5 Concentrations in Pennsylvania Counties. Regional Research Institutes Working Paper Series.

Frech, H. (1996). Competition and monopoly in medical care. Aei Pr.

Fredriksson, P. G., Wang, L., and Mamun, K. A. (2011). Are Politicians Office or Policy Motivated? The Case of US Governors' Environmental Policies. Journal of Environmental Economics and Management, 62(2):241-253.

Gbesemete, K. P. and Gerdtham, U.-G. (1992). Determinants of Health Care Expenditure in Africa: A Cross-Sectional Study. World development, 20(2):303-308.

Gerdtham, U.-G. and Jönsson, B. (2000). International Comparisons of Health Expenditure: Theory, Data and Econometric Analysis. In Handbook of health economics, volume 1, pages 11-53. Elsevier.

Getis, A. (2007). Reflections on Spatial Autocorrelation. Regional Science and Urban Economics, $37(4): 491-496$.

Griffith, D. A. (2013). Establishing Qualitative Geographic Sample Size in the Presence of Spatial Autocorrelation. Annals of the Association of American Geographers, 103(5):1107-1122.

Grossman, D. S., Slusky, D., et al. (2017). The effect of an Increase in Lead in the Water System on Fertility and Birth Outcomes: The Case of Flint, Michigan. West Virginia University College of Business and Economics Working Paper Series, (17-25). 
Guilfoos, T., Kell, D., Boslett, A., and Hill, E. L. (2017). The Economic and Health Effects of the 2014 Chemical Spill in the Elk River, West Virginia. American Journal of Agricultural Economics, 100(2):609-624.

Hausman, J. A. (1978). Specification Tests in Econometrics. Econometrica: Journal of the econometric society, pages 1251-1271.

Holly, A., Ke, X., and Saksena, P. (2011). The Determinants of Health Expenditure: A CountryLevel Panel Data Analysis. World Health Organisation Working Paper.

Hunter, P. R., MacDonald, A. M., and Carter, R. C. (2010). Water Supply and Health. PLoS medicine, 7(11):e1000361.

Jerrett, M., Eyles, J., Dufournaud, C., and Birch, S. (2003). Environmental Influences on Healthcare Expenditures: An Exploratory Analysis from Ontario, Canada. Journal of Epidemiology \& Community Health, 57(5):334-338.

Katsouyanni, K. (2003). Ambient Air Pollution and Health. British medical bulletin, 68(1):143-156.

Kelejian, H. H., Tavlas, G. S., and Hondroyiannis, G. (2006). A Spatial Modelling Approach to Contagion Among Emerging Economies. Open economies review, 17(4-5):423-441.

Kim, C. W., Phipps, T. T., and Anselin, L. (2003). Measuring the Benefits of Air Quality Improvement: A Spatial Hedonic Approach. Journal of environmental economics and management, $45(1): 24-39$.

Kleiman, E. (1974). The Determinants of National Outlay on Health. In The economics of health and medical care, pages 66-88. Springer.

Le Gallo, J., Ertur, C., and Baumont, C. (2003). A Spatial Econometric Analysis of Convergence Across European Regions, 1980-1995. In European regional growth, pages 99-129. Springer.

Leggett, C. G. and Bockstael, N. E. (2000). Evidence of the Effects of Water Quality on Residential Land Prices. Journal of Environmental Economics and Management, 39(2):121-144.

LeSage, J. and Pace, R. K. (2009). Introduction to Spatial Econometrics. Chapman and Hall/CRC.

LeSage, J. P. and Pace, R. K. (2014). Interpreting Spatial Econometric Models. Handbook of regional science, pages $1535-1552$.

List, J. A. and Sturm, D. M. (2006). How (e)lections Matter: Theory and Evidence from Environmental Policy. The Quarterly Journal of Economics, 121(4):1249-1281.

Liu, T., Opaluch, J. J., and Uchida, E. (2017). The Impact of Water Quality in Narragansett Bay on Housing Prices. Water Resources Research, 53(8):6454-6471.

MacKinnon, J. G., White, H., and Davidson, R. (1983). Tests for Model Specification in the Presence of Alternative Hypotheses: Some Further Results. Journal of Econometrics, 21(1):53-70.

Martin, J. J. M., Puerto López del Amo González, M., and Dolores Cano Garcia, M. (2011). Review of the Literature on the Determinants of Healthcare Expenditure. Applied Economics, 43(1):1946. 
Messner, M., Shaw, S., Regli, S., Rotert, K., Blank, V., and Soller, J. (2006). An Approach for Developing a National Estimate of Waterborne Disease Due to Drinking Water and a National Estimate Model Application. Journal of water and health, 4(S2):201-240.

Murthy, N. V. and Ukpolo, V. (1994). Aggregate Health Care Expenditure in the United States: Evidence from Cointegration Tests. Applied Economics, 26(8):797-802.

Narayan, P. K. and Narayan, S. (2008). Does Environmental Quality Influence Health Expenditures? Empirical Evidence from a Panel of Selected oecd Countries. Ecological economics, 65(2):367-374.

Naumova, E. N., Liss, A., Jagai, J. S., Behlau, I., and Griffiths, J. K. (2016). Hospitalizations Due to Selected Infections Caused by Opportunistic Premise Plumbing Pathogens (oppp) and Reported Drug Resistance in the United States Older Adult Population in 1991-2006. Journal of public health policy, 37(4):500-513.

Newhouse, J. P. (1977). Medical-Care Expenditure: A Cross-National Survey. The Journal of Human Resources, 12(1):115-125.

Organization for Economic Co-operation and Development (2017). Health at a Glance 2017: Oecd Indicators. http://www.oecd-ilibrary.org/social-issues-migration-health/health-at-a-glance2017_health_glance-2017-en. Accessed on 07/29/2018.

Pope III, C. A. and Dockery, D. W. (2006). Health Effects of Fine Particulate Air Pollution: Lines That Connect. Journal of the air \& waste management association, 56(6):709-742.

Prieto, D. C. and Lago-Peñas, S. (2012). Decomposing the Determinants of Health Care Expenditure: the Case of Spain. The European Journal of Health Economics, 13(1):19-27.

Qureshi, M. I., Khan, N. U., Rasli, A. M., and Zaman, K. (2015). The Battle of Health with Environmental Evils of Asian Countries: Promises to Keep. Environmental Science and Pollution Research, 22(15):11708-11715.

Raub, J. A., Mathieu-Nolf, M., Hampson, N. B., and Thom, S. R. (2000). Carbon Monoxide Poisoning-A Public Health Perspective. Toxicology, 145(1):1-14.

Reich, O., Weins, C., Schusterschitz, C., and Thöni, M. (2012). Exploring the Disparities of Regional Health Care Expenditures in Switzerland: Some Empirical Evidence. The european journal of health economics, 13(2):193-202.

Reinhardt, U. E. (2003). Does the Aging of the Population Really Drive the Demand for Health Care? Health Affairs, 22(6):27-39.

Sawyer, B. and Cox, C. (2018). How Does Health Spending in the US Compare to Other Countries? Kaiser Family Foundation.

Sullivan, T. J., Driscoll, C. T., Beier, C. M., Burtraw, D., Fernandez, I. J., Galloway, J. N., Gay, D. A., Goodale, C. L., Likens, G. E., Lovett, G. M., et al. (2018). Air Pollution Success Stories in the United States: The Value of Long-Term Observations. Environmental science $\mathscr{G}$ policy, 84:69-73.

Thornton, J. A. and Rice, J. L. (2008). Determinants of Healthcare Spending: A State Level Analysis. Applied Economics, 40(22):2873-2889. 
Tuttle, C. M. and Heintzelman, M. D. (2015). A Loon on Every Lake: A Hedonic Analysis of Lake Water Quality in the Adirondacks. Resource and Energy Economics, 39:1-15.

U.S. Environmental Protection Agency. (2004). Epa Claims to Meet Drinking Water Goals Despite Persistent Data Quality Shortcomings (report no. 2004-p-0008). https://www.epa.gov/sites/production/files/2015-12/documents/20040305-2004-p-0008.pdf. Accessed on $03 / 02 / 2018$.

U.S. Environmental Protection Agency. (2010). Revised Total Coliform Rule: A Quick Reference Guide. https://www.epa.gov/sites/production/files/2015-12/documents/20040305-2004-p0008.pdf. Accessed on 04/02/2018.

U.S. Environmental Protection Agency. (2013). Providing Safe Drinking Water in America: 2013 National Public Water Systems Compliance Report. https://www.epa.gov/sites/production/files/2015-06/documents/sdwacom2013.pdf. Accessed on $04 / 06 / 2018$.

U.S. Environmental Protection Agency. (2014). Speech: Administrator Gina McCarthy, Remarks Celebrating the 40th Anniversary of the Safe Drinking Water Act, as Prepared. https://archive.epa.gov/epapages/newsroom_archive/speeches/21a0a07494e97f3985257da9006ad 9d0.html. Accessed on 04/06/2018.

U.S. Environmental Protection Agency. (2018a). Drinking Water Contaminant Human Health Effects Information. https://www.epa.gov/dwstandardsregulations/drinking-water-contaminanthuman-health-effects-information. Accessed on 01/07/2018.

U.S. Environmental Protection Agency. (2018b). Progress Cleaning the Air and Improving People's Health. https://www.epa.gov/dwstandardsregulations/drinking-water-contaminant-humanhealth-effects-information. Accessed on 01/05/2018.

U.S. Geological Survey (2009). Contamination in U.S. Private Wells. https://water.usgs.gov/edu/gw-well-contamination.html. Accessed on 05/05/2018.

Villanueva, C. M., Kogevinas, M., Cordier, S., Templeton, M. R., Vermeulen, R., Nuckols, J. R., Nieuwenhuijsen, M. J., and Levallois, P. (2014). Assessing Exposure and Health Consequences of Chemicals in Drinking Water: Current State of Knowledge and Research Needs. Environmental health perspectives, 122(3):213-221.

Wallsten, S. and Kosec, K. (2008). The Effects of Ownership and Benchmark Competition: An Empirical Analysis of US Water Systems. International Journal of Industrial Organization, 26(1):186205.

Wang, Z. (2009). The Determinants of Health Expenditures: Evidence from US State-Level Data. Applied Economics, 41(4):429-435.

Wilson, R. M. (1999). Medical Care Expenditures and GDP Growth in OECD Nations. American Association of Behavioral and Social Sciences Journal, 2(3):159-171.

World Health Organization (2018). The Determinants of Health. https://www.who.int/hia/evidence/doh/en/index3.html. Accessed on 01/09/2018. 
Yahaya, A., Nor, N. M., Habibullah, M. S., Ghani, J. A., and Noor, Z. M. (2016). How Relevant Is Environmental Quality to Per Capita Health Expenditures? Empirical Evidence from Panel of Developing Countries. SpringerPlus, 5(1):925.

Zou, X., Azam, M., Islam, T., and Zaman, K. (2016). Environment and Air Pollution Like Gun and Bullet for Low-Income Countries: War for Better Health and Wealth. Environmental Science and Pollution Research, 23(4):3641-3657. 